\title{
The biosynthesis of pyoverdines
}

\author{
Michael T. Ringel ${ }^{1}$ and Thomas Brüser ${ }^{1, *}$ \\ ${ }^{1}$ Institute of Microbiology, Leibniz University Hannover, Herrenhäuser Str. 2, 30419 Hannover, Germany. \\ * Corresponding Author: \\ Thomas Brüser, Institute of Microbiology, Leibniz Universität Hannover, Herrenhäuser Str. 2, 30419 Hannover, Germany; Tel. +49 511 \\ 762 5945; Fax: +49 511762 5287; E-mail: brueser@ifmb.uni-hannover.de
}

\begin{abstract}
Pyoverdines are fluorescent siderophores of pseudomonads that play important roles for growth under iron-limiting conditions. The production of pyoverdines by fluorescent pseudomonads permits their colonization of hosts ranging from humans to plants. Prominent examples include pathogenic or non-pathogenic species such as Pseudomonas aeruginosa, $P$. putida, $P$. syringae, or $P$. fluorescens. Many distinct pyoverdines have been identified, all of which have a dihydroxyquinoline fluorophore in common, derived from oxidative cyclizations of non-ribosomal peptides. These serve as precursor of pyoverdines and are commonly known as ferribactins. Ferribactins of distinct species or even strains often differ in their sequence, resulting in a large variety of pyoverdines. However, synthesis of all ferribactins begins with an LGlu/D-Tyr/L-Dab sequence, and the fluorophore is generated from the DTyr/L-Dab residues. In addition, the initial L-Glu residue is modified to various acids and amides that are responsible for the range of distinguishable pyoverdines in individual strains. While ferribactin synthesis is a cytoplasmic process, the maturation to the fluorescent pyoverdine as well as the tailoring of the initial glutamate are exclusively periplasmic processes that have been a mystery until recently. Here we review the current knowledge of pyoverdine biosynthesis with a focus on the recent advancements regarding the periplasmic maturation and tailoring reactions.
\end{abstract}

doi: 10.15698/mic2018.10.649

Received originally: 14.05.2018;

in revised form: 26.06.2018,

Accepted 03.07.2018,

Published 28.08.2018.

Keywords: Pyoverdines, iron starvation, siderophores, Pseudomonas fluorescens, Pseudomonas aeruginosa, non-ribosomal peptide synthetases, periplasmic tailoring.
Abbreviations:
3-Oxo- $\mathrm{C}_{12}$-HSL - N-(3-oxododecanoyl)-L- homoserine lactone,
$\mathrm{C}_{4}$-HSL - N-butanoyl-L-homoserine lactone,
L-ASA - L-aspartate B-semialdehyde, L-Dab - L-2,4-diaminobutyrate, L-fOHOrn - L- $\mathrm{N}_{5}$-formyl- $\mathrm{N}_{5}$-hydroxy ornithine,
NRPS - non-ribosomal peptide synthetase,
Ntn - N-terminal nucleophile,
$P L P$ - pyridoxal 5'-phosphate.

\begin{abstract}
A BRIEF HISTORY OF PYOVERDINE RESEARCH
In 1892, Gessard discovered yellow-green fluorescent pigments of bacterial origin that he termed fluorescins [1]. These pigments, which later have been renamed pyoverdines by Turfreijer [2], could be discolored by acidification, and they recovered their color upon neutralization [1]. It was proposed by Turfitt in 1936 that the ability to produce these green pigments may be used for classification purposes [3]. Pyoverdine-producing bacteria are known today to belong to the genus Pseudomonas and form a subgroup therein, referred to as "fluorescent pseudomonads". Pyoverdines from various strains have also been termed "pseudobactins", beginning with a publication that introduced this term based on claimed but not further detailed chemical and physical differences to known siderophores
\end{abstract}

[4]. Subsequent structural analyses did not reveal any distinguishing characteristics to pyoverdines [5]. In fact, the "pseudobactin" structure was the first solved structure of a pyoverdine, but the name pseudobactin still occasionally occurs in literature.

First functional insights were based on studies by King and coworkers who described in 1948 the induction of fluorescin (= pyoverdine) production by $P$. aeruginosa under iron limitation [6]. Totter and Moseley found in 1952 that the production is inversely correlated with the logarithm of the iron concentration over a wide range [7]. It took 26 years, until the next major progresses regarding pyoverdine function were made. In 1978, Meyer and coworkers first determined the extremely high affinity of pyoverdine to iron that is in the range of $10^{32}$ [8], before they finally revealed the function of pyoverdine in iron 
uptake [9]. It was concluded that pyoverdines are siderophores, which are iron-binding chelators involved in irontransport into the cell [10]. In agreement with this function, it later turned out that the production of pyoverdines is tightly regulated in response to iron by the regulator Fur $[11,12]$. This review focuses on the biosynthesis and secretion of pyoverdines as summarized in Figure 1. For a more detailed summary on the discovery and earlier studies of pyoverdines, the reader is referred to an earlier excellent review [13].

\section{CYTOPLASMIC INITIATION OF PYOVERDINE BIOGENE-} SIS

The elucidation of the first pyoverdine structure [5] led to a new era in pyoverdine research that focused on the biosynthesis. Pyoverdines (Figure 2A) are generally composed of i) a characteristic 2,3-diamino-6,7-dihydroxyquinoline fluorophore, ii) a variable acyl side chain attached to the 3amino group of the fluorophore, and iii) a strain-specific peptide backbone, usually bound to the $\mathrm{C}_{1}$-carboxyl group of the ring system (reviewed in $[14,15])$, although so called

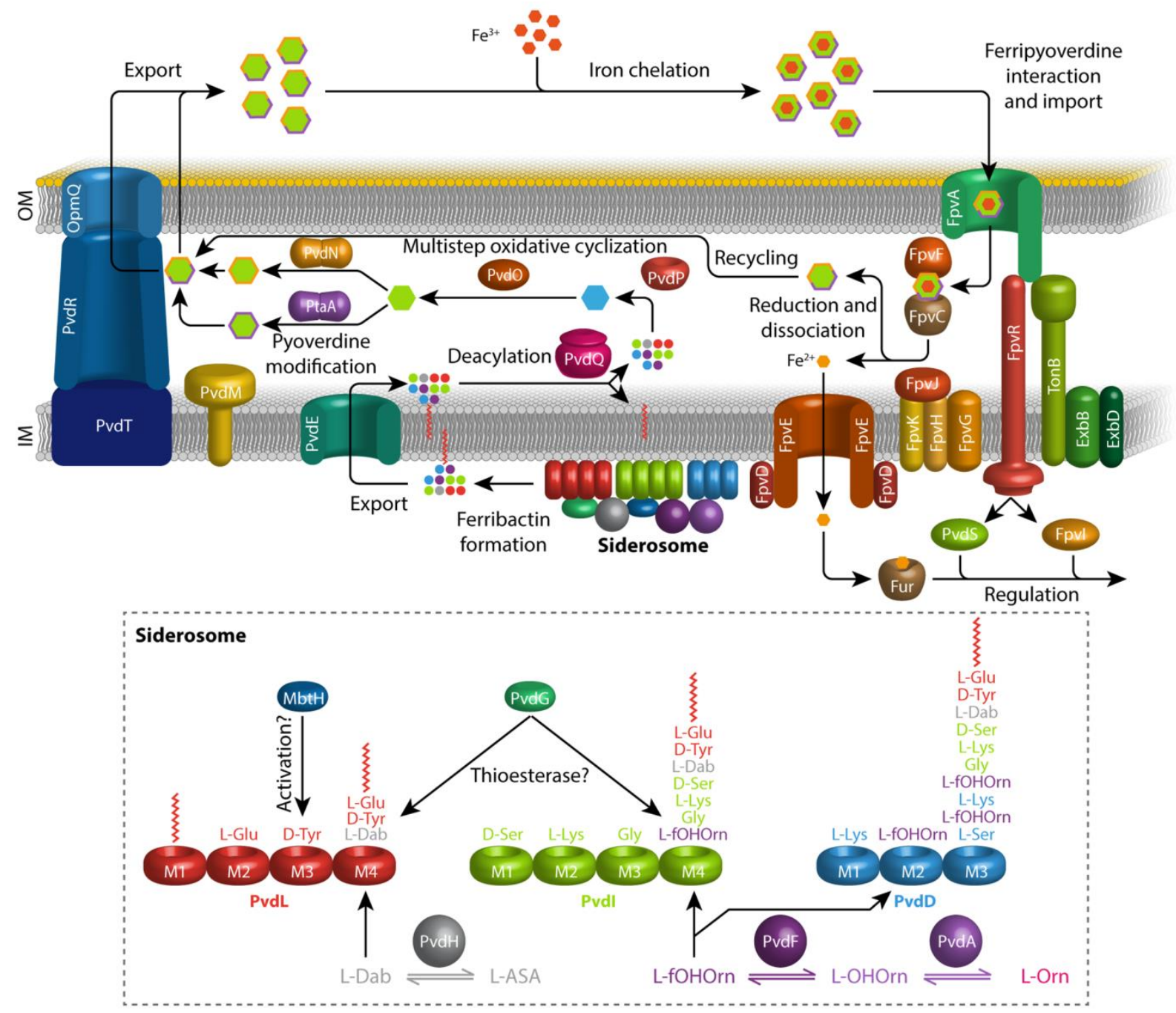

FIGURE 1: Current model for the biosynthesis, secretion, uptake and recycling of pyoverdines in P. fluorescens A506. The acylated ferribactin precursor is synthesized in the cytoplasm by NRPSs and auxiliary enzymes organized in membrane associated complexes termed "siderosomes". The cytoplasmic synthesis is detailed in the box at the bottom. PvdL synthesizes the conserved N-terminal tripeptide with its acylation, the other NRPS are responsible for rest of the peptide and therefore vary between strains with distinct sequences. The auxiliary enzymes MbtH, PvdG, PvdH, PvdA, PvdF, and PvdD play the indicated roles (see text for details). The acylated ferribactin is exported most likely by PvdE into the periplasm, where it is deacylated by the Ntn-type hydrolase PvdQ. Subsequently, PvdP catalyzes the oxidative cyclization, resulting in dihydropyoverdine. PvdO, possibly in conjunction with other proteins, facilitates the final oxidation, yielding the characteristic pyoverdine chromophore. Thereafter, side-chain modification-pathways transform the original L-glutamic acid side chain either to the succinamide, catalyzed by PvdN, or the $\alpha$-ketoglutarate, catalyzed by PtaA. The modified pyoverdines are then secreted via various transport systems such as PvdRT-OmpQ, and bind outside ferric iron. The complex binds to FpvA and is TonB-dependently taken up. FpvF and FpvC reduce and dechelate the iron, which is taken up by the FpvDE transporter. The apo pyoverdine is recycled. See text for details. 
isopyoverdines exist that have the peptide backbone attached to the $C_{3}$-carboxyl group $[16,17]$. The strain-specific peptide backbone varies in its sequence and can either be linear or (partially) intramolecularly cyclized. Furthermore, it can contain a number of unusual amino acids, such as $\beta$ hydroxy aspartic acid, $\beta$-hydroxy histidine, ornithine, cyclo$N_{5}$-hydroxy ornithine, $N_{5}$-formyl- $N_{5}$-hydroxy ornithine, $N_{5}$ acetyl- $N_{5}$-hydroxy ornithine and $N_{5}$-hydroxybutyryl- $N_{5}$ hydroxy ornithine, of which the hydroxamates or $\beta$ hydroxy carboxylates contribute to iron-chelation. Additionally, the amino acids in the peptide backbone may also be isomerized to the D-enantiomeric form $[13,14]$.

Pyoverdine biogenesis starts in the cytoplasm, where non-ribosomal peptide synthetases (NRPSs) such as PvdL [18], Pvdl [19] and PvdD [20, 21] (depending on the strain) assemble an initially acylated ferribactin, the peptide precursor for pyoverdines [22]. NRPSs are modular enzymes that add specific amino acids, one per module, to a growing peptide [23]. Each module first adenylates its cognate amino acid at an adenylation domain and transfers it to a free thiol of a covalently bound phosphopantetheine cofactor. The peptide bonds are formed at condensation domains of the modules, thereby transferring growing peptides onto the phosphopantetheine-bound amino acid of the next module. Additional tayloring reactions and epimerizations can be catalyzed by specific domains [24]. Finally, a thioesterase must cleave the thioester bond to release the peptide from the phosphopantetheine cofactor of the last module. Module 1 of PvdL incorporates either a myristic- or myristoleic acid side-chain instead of an amino acid as first building block $[25,26]$, which is why ferribactin is acylated on the free amino group of the first incorporated amino acid. The first three amino acids of ferribactins, which are also incorporated by PvdL, are always L-glutamic acid (L-Glu), coupled via its $\gamma$-carboxy group to $D$-tyrosine (D-Tyr) and L-2,4-diaminobutyrate (L-Dab). This is important as the characteristic chromophore is derived from the D-Tyr and L-Dab residues, and we will later see that also the L-Glu residue at the $\mathrm{N}$-terminus seems to be important, as several enzymes are produced that modify this residue.

The unusual amino acids in ferribactin are synthesized by pyoverdine-specific biosynthetic enzymes. L-Dab is produced by $\mathrm{PvdH}$ from L-aspartate $\beta$-semialdehyde (L-ASA) [27], whilst L- $N_{5}$-formyl- $N_{5}$-hydroxy ornithine (L-fOHOrn) is produced in two steps from L-ornithin by PvdA-dependent hydroxylation [28-31] and PvdF-dependent formylation [32]. It has been proposed that all these enzymes, together with the NRPSs, may form a membrane associated complex termed "siderosome", which could circumvent cytoplasmic toxicity $[33,34]$.

Beside these enzymes, a small MbtH like protein has also been found to be associated with NRPSs of cytoplasmic ferribactin synthesis [35]. The structure of this protein from $P$. aeruginosa has been solved and it was demonstrated to play a role in pyoverdine production or secretion [36]. MbtH proteins have been shown to enhance the activity of NRPS adenylation domains to a variable extent [35, 37], but the specific function of the MbtH like protein in ferribactin biosynthesis is unclear. Also, a soluble thioesterase PvdG has been implied to be involved in pyoverdine production [38]. The corresponding gene pvdG is organized together with $p v d L$, and an interposon mutagenesis of pvdG abolished pyoverdine production [38]. As only the last NRPSs of ferribactin synthesis, PvdD, has been shown to possess its own thioesterase active site motif [20], it may be that PvdG provides that functionality in trans for PvdL and possibly also for Pvdl (Figure 1). PvdG might have overlapping function with a potential second soluble thioesterase (PA2411) [39], which could explain why its genetic inactivation did not abolish pyoverdine production [38]. In specific strains, further auxiliary enzymes can be involved in cytoplasmic ferribactin biosynthesis steps. For example, there exist $P$. aeruginosa strains that produce a pyoverdine with an $\mathrm{N}$-hydroxy-cyclo-ornithine residue, the so-called type-Il pyoverdine, and a specific acylationprotein, $\mathrm{PvdY}_{\text {II, }}$ is responsible for this [40]. It is believed that most likely an acetylation of $N$-hydroxy-ornithine is required for the cyclization at some stage before the peptide is released from the NRPS [40].

\section{PERIPLASMIC COMPLETION OF PYOVERDINE SYNTHESIS \\ Transport of the ferribactin precursor - some questions remain}

The acylated ferribactin is most likely immediately translocated across the cytoplasmic membrane into the periplasm by the $A B C$ transporter PvdE $[41,42]$. The best evidence for this role comes from genetic studies that demonstrated abolished pyoverdine secretion in a PvdE interposon deletion mutant of strain $P$. aeruginosa PAO1, and the complementation of this phenotype by expression of the $p v d E$ gene [42]. Notably, that study showed that the $p v d E$ mutant also did not display any periplasmic pyoverdine fluorescence anymore, indicating that PvdE must interfere with a step prior to fluorophore formation, which could well be ferribactin transport. A potential role in transport of the pyoverdine precursor has also been suggested in bioinformatic studies, that categorized PvdE to a class of $A B C$ transporters for modified cyclic peptides [43]. Interestingly, two older experimental studies had already inactivated the $p v d E$ gene with somewhat different results. The inactivation of $p v d E$ in $P$. aeruginosa OT11 resulted in complete absence of pyoverdine in culture supernatants [41], whereas a transposon mutagenesis study identified four clones of strain PAO1 MT1 with inactivating insertions in $p v d E$ that all showed a specific lower fluorescence in the culture supernatant [44]. However, this fluorescence was not acid-quenchable and thus the compound was not pyoverdine. Instead it was speculated to represent a precursor of pyoverdine or a degradation product [44]. A transport of acylated ferribactin by PvdE has not yet been demonstrated in vitro, and the absence of fluorescence in the periplasm might certainly also have other reasons, albeit the transporter function is definitively the most likely scenario. 


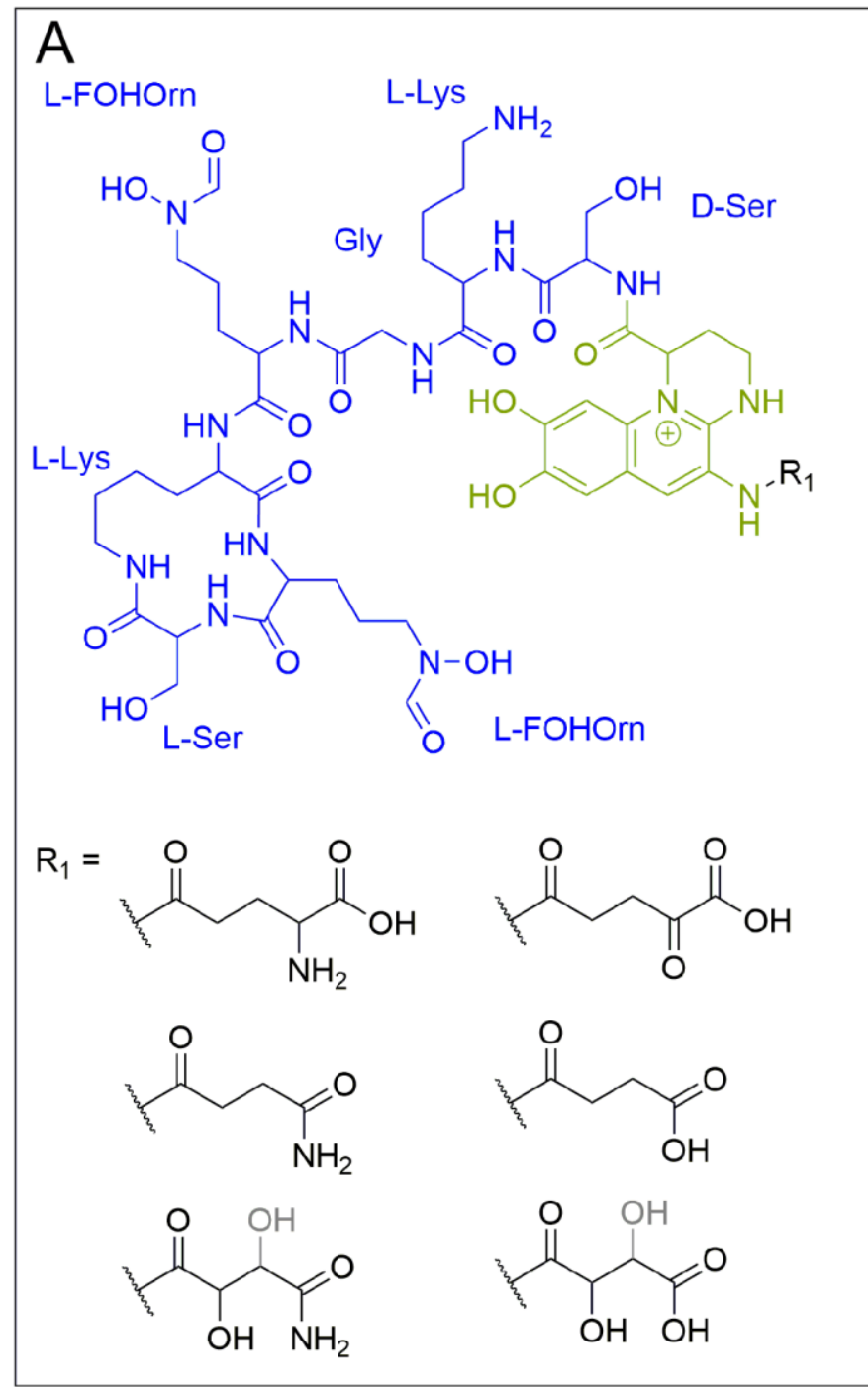

\section{C}<smiles>[R]NC(Cc1ccc(O)cc1)C1=NC(C([R])=O)CCN1</smiles>

PvdP +1/2 $\mathrm{O}_{2} \downarrow$

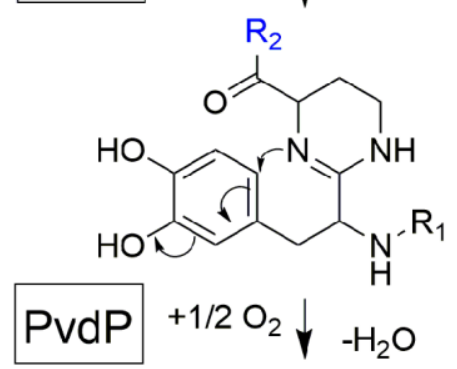<smiles>[Y]CCC(I)C([R])=O</smiles>

$\mathrm{H}^{+}$<smiles>[R1]NC1CC2=CC(=O)C(=O)C=C2C=NC1=N</smiles>

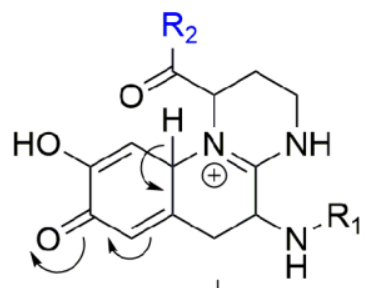<smiles></smiles>

B<smiles>[R2]C(=O)C(CCN)NCC(=O)NCCCO</smiles>

$\mathrm{HO}$ initial product of NRPS

Ferribactin 
Deacylation of the ferribactin precursor - quorum signaling meets pyoverdine production

In the periplasm, the acylation of ferribactin is removed by the Ntn-type hydrolase PvdQ [25, 45]. This now established function was first proposed by Visca et al. [23]. PvdQ was initially discovered as quorum-quenching enzyme, which acts by deacylating the autoinducer $\mathrm{N}$-(3-oxododecanoyl)L-homoserine lactone (3-Oxo- $\mathrm{C}_{12}-\mathrm{HSL}$ ) by hydrolysis of its amide bond [46]. The enzyme is produced as a proenzyme that autoproteolytically cleaves itself in the periplasm by excising a 23-residue spacer forming an $18 \mathrm{kDa} \alpha$-chain and a $60 \mathrm{kDa} \beta$-chain, which reassociate to form a functional heterodimer [46]. It is an interesting aspect that pathways of quorum sensing and pyoverdine production converge in PvdQ, which is a true bifunctional enzyme. The function of PvdQ in quorum sensing of $P$. aeruginosa is believed to alter the ratio between the two autoinducers found in this species, namely the PvdQ substrate 3-Oxo- $\mathrm{C}_{12}-\mathrm{HSL}$ and the short-chain autoinducer $\mathrm{N}$-butanoyl-L-homoserine lactone $\left(\mathrm{C}_{4}-\mathrm{HSL}\right)$, which is believed to specifically adapt gene expression to specific host environments [47]. $\mathrm{C}_{4}-\mathrm{HSL}$ is not a substrate of PvdQ [48]. A good example for effects of an altered ratio between the two autoinducers may be the effect of markedly reduced pyocyanine production in response to reduced 3-Oxo- $\mathrm{C}_{12}-\mathrm{HSL}$ levels [48]. Pyocyanine generates oxidative stress and harms host organs [49]. It thus might not be coincidental that pyoverdine production, which depends on the presence of PvdQ, is coupled with a reduction of host-threatening virulence: Both may serve to establish a permanent stable habitat in the host. A phenotypic analysis of a $p v d Q$ deletion mutant of $P$. aeruginosa strain PAO1 indicated that PvdQ is required for swarming, biofilm formation and virulence [50]. While the swarming and virulence phenotypes could be attributed to the absence of pyoverdine, the biofilm defect could not be suppressed by external addition of pyoverdine and thus may relate to quorum sensing. Interestingly, the production of PvdQ is tightly regulated and induced under iron-limiting conditions, which is another support for the idea that the effects of PvdQ on quorum sensing are specifically required when pyoverdines are produced [50]. It would be good to know why all ferribactins initially need to be acylated and deacylated again after transport. One reason could be a membrane attachment that could help to anchor the precursor compound at the cytoplasmic membrane, which may improve the efficiency of the synthesis at clustered siderosomes or help to avoid its diffusion into the cytoplasm and thereby could guarantee its efficient transport. Another reason could be some mechanistic requirement for the transport system. A third reason may simply be the introduction of a biogenesis step that is controlled by an enzyme, which coordinates pyoverdine production with quorum sensing and virulence. As PvdQ influences the adaptation of fluorescent pseudomonads to host environments, it has been considered as target for inhibitors that hopefully may help to reduce the ability to thrive in hosts by blocking pyoverdine synthesis. After having solved the structure of PvdQ from $P$. aeruginosa, researchers succeeded in identifying such inhibitors, which were capable to inhibit growth of $P$. aeruginosa under iron-limiting conditions [51-53].

\section{Periplasmic formation of the fluorophore - the central roles of PvdP and PvdO}

After ferribactin is deacylated, the fluorescent dihydroxyquinoline ring system is generated, which transforms the ferribactin into a pyoverdine. This ring system is strictly conserved in pyoverdines and provides a planar scaffold for two oxo-ligands of the siderophore. As mentioned before, ferribactin is always synthesized with the three $\mathrm{N}$ terminal residues L-Glu/D-Tyr/L-Dab, and the tyrosine and diaminobutyrate residues of these form the fluorophore [54]. In ferribactin, L-Dab 4-amino group is condensed with the carbonyl group of the neighboring D-Tyr (Figure 2B). An oxidative cyclization cascade as proposed by Dorrestein et al. [55] likely results in the formation of the three-ring fluorophore (Figure $\mathbf{2 C}$ ). In that oxidative cyclization cascade, the tyrosine side chain is first hydroxylated to form a catechol that is then oxidized to an o-quinone. This facilitates the intramolecular addition, involving the 1-amino nitrogen atom from the neighboring L-Dab cycle and the quinone ring, resulting after tautomerization in the dihydro-dihydroxyquinoline system of dihydropyoverdine. The initial hydroxylation and oxidation steps are catalyzed by the copper-containing tyrosinase PvdP [56], which thereby also promotes the cyclization and formation of the dihydropyoverdine. This study observed a completion of the fluorescent fluorophore in the in vitro PvdP activity assays and suggested that PvdP is responsible for the complete fluorophore formation [56], which contrasted earlier studies that proposed the existence of an iron-enzymecatalyzed oxidation of dihydropyoverdine [57]. Also the detection of secreted dihydropyoverdine in a Pseudomonas strain supported the view that a single enzyme does not catalyze the complete conversion of ferribactin to the final fluorophore [58]. Indeed, a rapid autoxidation can in principle complete the fluorophore under alkaline conditions [59], but recent studies demonstrated that this does not occur under weakly acidic physiological conditions, as found in the periplasmic space [60]. It could be shown that a mutant strain lacking the putative oxidoreductase PvdO produced the dihydropyoverdines, indicating that PvdP catalyzes only the initial hydroxylation and first oxidation, whereas the final oxidation depends on PvdO [60]. PvdO as purified from a heterologous Escherichia coli system did not contain a detectable cofactor and was inactive [60]. It remains to be clarified whether active PvdO can be obtained that carries out the second oxidation alone, or whether it needs to associate with other components, such as specific electron transport systems or possibly the enzyme PvdP. Importantly, PvdO and PvdP always occur together, and currently both seem to be the only enzymes that are directly involved in the formation of the pyoverdine fluorophore [60].

As alternative to the above described oxidative cyclization cascade [55], a mechanism has been postulated based on the observation of a trihydroxylated "pseudoverdin" that was produced by a pyoverdine deficient mutant of 
P. aeruginosa PAO1, which was complemented by a cosmid gene bank clone to re-established fluorescence [61]. The trihydroxylated "pseudoverdin" in that strain was not functional in iron acquisition and it was essentially an artificial system with unidentified genetic elements, but the resulting structure could permit an intramolecular Bucherer reaction as basis for the ring formation. Based on the identification of dihydropyoverdine-7-sulfonic acids, it was also proposed that a sulfonation can occur to facilitate this intramolecular Bucherer reaction [62, 63]. However, sulfonated dihydropyoverdines appear to be very lowly abundant and they might represent adducts of media constituents to the reactive dihydropyoverdine. As the conversion of dihydropyoverdine to pyoverdine most likely requires only one further enzyme, PvdO, and as the pvdO mutant did not accumulate a sulfonated dihydropyoverdine, we think that the Bucherer pathway is unlikely to be realized in this biosynthesis.

The electron transport pathways that are involved in the oxidation reactions are of fundamental importance and have not yet been clarified. Most relevant in this respect are studies with $P$. fluorescens ATCC17400, which show that the periplasmic membrane-associated oxidoreductase CcmC is involved [64-66]. CcmC is well-known for its role as hemochaperone in periplasmic c-type cytochrome biogenesis [67-70], but it does not seem to be the cytochrome biogenesis role of $\mathrm{CcmC}$ that is relevant for its pyoverdine-related role. A very interesting mutagenesis study could dissect both functions of $\mathrm{CcmC}$, indicating that distinct regions of this protein are involved in the two processes [66]. The inactivation of $\mathrm{CmC}$ has been described to reduce the level of thiol-oxidation in the periplasm, suggesting that oxidized thiols or more generally the oxidation-power in the periplasm may be relevant for pyoverdine formation [64]. In this context, it is interesting that the addition of cysteine to the growing $\mathrm{ccmC}$ mutant culture resulted in formation of ferribactin [64]. As it is now clear that PvdP is responsible for the conversion of ferribactin to dihydropyoverdine, it is likely that electrons must be transferred from PvdP to a periplasmic redox active compound that requires $\mathrm{CcmC}$ functionality.

\section{The side chain modifications - surprising periplasmic reactions catalyzed by PvdN and PtaA}

While the conservation of the residues D-Tyr/L-Dab at positions 2 and 3 in all ferribactins is required for fluorophore biosynthesis, the conservation of the L-Glu at position 1 in ferribactins is not that easy rationalized. This acidic residue forms an amide bond via its $\gamma$-carboxylic group to D-Tyr and thus possesses free $\alpha$-carboxy and $\alpha$-amino groups. Importantly, mature pyoverdines usually do not contain these residues any more. Instead, depending on the strain analyzed, they usually possess a succinamide, succinate or $\alpha$-ketoglutarate at this position, and sometimes malamide and malic acid are found, or even traces of intramolecular cyclized succinic acid (Figure 3). P. aeruginosa, for example, converts the glutamate completely to succinamide, succinate or $\alpha$-ketoglutarate. It is unknown, why these modifications are made, but it has been speculated that they could play a role under specific environmental conditions or niches that could so far not be mimicked in pure cultures under laboratory conditions [71].

Until recently, no enzyme could be identified as being responsible for these "tailoring" modifications. The reason for this was the fact that the candidate proteins, the functionally uncharacterized periplasmic enzymes encoded in pyoverdine biosynthesis gene clusters, were believed to be essential for pyoverdine formation [38]. Three of these periplasmic enzymes, PvdM, PvdN, and PvdO, are usually encoded in an operon. Interposon mutagenesis of the corresponding genes in $P$. aeruginosa indicated essential roles of these genes in pyoverdine biosynthesis, although it was already noted in the first of these studies that complementation analyses were required to exclude polar effects in the pvdMNO operon [38, 42, 72]. In recent studies that used in frame deletions and complementations in $P$. fluorescens strain A506, which produces the same pyoverdine modifications as $P$. aeruginosa, it turned out that only the first gene in this operon is indeed essential, whereas PvdO is not essential, being responsible only for the final oxidation step of the fluorophore (see above), and the absence of PvdN resulted only in abolished formation of succinamide and succinic acid [71]. This study therefore revealed the first tailoring enzyme for the periplasmic glutamic acid modification. PvdN is an interesting enzyme for two reasons: (i) It is a PLP-containing enzyme that catalyzes a new PLP-dependent reaction mechanism, a decarboxylation under retention of an amino group at the $\alpha$-carbon atom [71], and (ii) it is transported by the twin-arginine translocation system as folded protein that requires cytoplasmic PLP binding to be transport competent $[71,73]$. When the active site lysine is mutated, PvdN remains stuck in the membrane, most likely due to transport-incompatible, unfolded hydrophobic regions [71]. As PvdN catalyzes the direct formation of succinamide from glutamate and is also required for the occurrence of succinate that is most likely the spontaneous hydrolysis product of succinamide, the formation of $\alpha$-ketoglutarate from glutamate requires another enzyme, which recently turned out to be a novel PLPcontaining transaminase, termed PtaA for "periplasmic transaminase $A^{\prime \prime}$ [74]. PtaA is usually encoded outside the large pyoverdine gene clusters, but an interesting exception has been recognized ( $P$. putida $\mathrm{H} 8234)$ where its gene substitutes the gene encoding PvdN. There are pyoverdineproducing pseudomonads that have both enzymes, PvdN and PtaA, some have only PvdN, and others only PtaA. Consequently, some strains produce the products of both biosynthesis branches, whereas others produce only products of one or the other branch [71, 74].

PtaA is a "normal" PLP-containing transaminase. As PtaA is also present in a number of species incapable of pyoverdine production, it has been suggested to also be involved in other periplasmic biosynthesis pathways, which is why it received the general name "periplasmic transaminase $A^{\prime \prime}$ [74]. What is surprising and what makes this enzyme unusual is simply the fact that it is active in the periplasm. Like PvdN, PtaA is transported together with its PLP cofactor in a folded conformation via the twin-arginine 
<smiles>CC(C)NC(=O)CCC(N)C(=O)O</smiles><smiles>CC(C)NC(=O)CCC(N)=O</smiles>

a-ketoglutaric acid
FIGURE 3: The branched periplasmic pathways for pyoverdine tailoring. PvdN generates the succinamide residue and PtaA the $\alpha$-ketoglutarate residue from glutamate. An unknown enzyme converts succinamide (most likely) or possibly glutamic acid to malamide in some species. The lower abundant succinic acid and malic acid pyoverdine forms are likely hydrolysis products of the corresponding amides. Note that the exact position of the hydroxyl group in malamide and malic acid residues is not resolved.<smiles>CCNC(=O)CCC(=O)O</smiles>

succinic acid intramolecular $\downarrow$ cyclization<smiles>[R7]C(=O)C1CCN2C(=O)CCC(=O)NC3=Cc4cc(O)c(O)cc4[N+]3=C2N1CC(Cl)(Cl)C(Cl)(Cl)Cl</smiles>

protein translocation pathway [74]. The cofactor thus enters the periplasm together with its protein in a tightly bound form, and it can therefore be assumed that the PLP is somehow regenerated from pyridoxamine after each reaction cycle inside the periplasm. Together, the recent advancements in the field established that there are two independent branches for the glutamate substitution in $P$. aeruginosa and $P$. fluorescens strains, which are (i) the PvdN-dependent branch that results in the succinamide and succinic acid as well as the intramolecular cyclization product, and (ii) the PtaA-dependent branch that results in $\alpha$-ketoglutarate. There is nothing known about the biosynthesis of the rarely occurring malamide and malate forms of pyoverdines yet, which are not present in the current pyoverdine biosynthesis model organisms $P$. aeruginosa PAO1 and P. fluorescens A506. While it is likely that the malate is the hydrolysis product of the malamide, the malamide could in principle be formed by an unknown hydroxylating enzyme that acts on succinamide. The introduction of the hydroxyl group might also occur earlier, but a hydroxylated glutamate intermediate has never been found, suggesting some direct transformation of succinamide to malamide.
Reactions of periplasmic pyoverdine biogenesis may not occur in a strict order

When PvdN is removed, PtaA converts all the pyoverdine to its $\alpha$-ketoglutarate form. Conversely, the lack of PtaA results in the succinamide and succinic acid forms generated by PvdN. Removal of both tailoring enzymes leaves the original glutamate unaltered [74]. It is tempting to assume that the tailoring steps occur after formation of the fully oxidized fluorescent pyoverdine. However, this may not be the case. The dihydropyoverdine formed by $p v d O$ deletion strains is accepted by PvdN as well as by PtaA as the correspondingly modified dihydropyoverdine forms have been found [60]. Apparently, the planarity of the attached ring system is not a prerequisite for substrate binding to these enzymes. Moreover, Budzikiewicz et al. detected a ferribactin with a succinamide side-chain [75], demonstrating that PvdN may even accept ferribactin as substrate, which shows that the ring system is not really relevant for the tailoring enzymes PvdN and PtaA. It is so far unknown to which extent the intermediates can be channeled from one enzyme to the next, but there is no evidence yet for such a channeling that could impose an order of events. 
GLOBAL TRADE ASPECTS - EXPORT, IMPORT, RECYCLING, AND REGULATION

\section{Export of pyoverdines - More than one way out}

After having summarized the knowledge about the enzymology of the biosynthesis steps, aspects of export, uptake, recycling and regulation need to be addressed to understand the physiology of pyoverdine biosynthesis. Pyoverdines can be exported via a transport system consisting of PvdR, PvdT, and OpmQ [76-78]. This system has originally been shown to be involved in the secretion of pyoverdine that has been taken up from the environment and thus is recycled for multiple use $[77,78]$, and later its involvement in transport of de novo synthesized pyoverdine was demonstrated [76]. However, the PvdRT-OpmQ transporter cannot be the only export route, as strains mutated in this system are still able to secrete pyoverdines, albeit an accumulation in the periplasm has been demonstrated in such strains [76]. Also a MexAB-OprM transporter has been implicated in pyoverdine secretion [79-81], but later studies indicate that the inactivation of this transporter had no significant effect on pyoverdine secretion [78]. However, that study also indicated that the inactivation of the PvdRT-OpmQ system reduced pyoverdine secretion only to about $50-60 \%$, which shows that also other systems must be involved. In $P$. taiwanensis, a type VI secretion system has been shown to mediate secretion of newly synthesized pyoverdine, and this study reports that the PvdRTOmpQ system is not relevant for this process in their organism [82]. Taken together, there is still considerable need to clarify under which conditions PvdRT-OmpQ systems are not only involved in recycling but also in secretion of de novo synthesized pyoverdines, and there is evidence that more not yet assigned transport systems are important.

\section{Import of pyoverdines - iron acquisition and siderophore recycling}

Organisms, especially those that live on or in host organisms, compete for the limited iron resources. Therefore, siderophore-uptake systems are usually specific for the siderophore that is used by the organism. Pyoverdines possess a highly variable, often even strain specific peptide moiety that confers distinguishable properties to the siderophore that can be taken up by differing uptake systems $[13,83,84]$. Nonetheless, pyoverdine uptake systems exist that can use distinct pyoverdines of other strains [83]. In the outer membrane, FpvA has been identified to be the ferripyoverdine receptor that recognizes iron-loaded pyoverdines [85, 86]. Its gene was cloned in 1993 [87], and its structure was later elucidated in great detail [88-90]. A number of mutational studies tried to elucidate the residues involved in pyoverdine binding, signaling and transport [91-93]. In 2009 it could be demonstrated by Greenwald et al. [94], that the first amino acid residues in the peptide backbone of pyoverdine determine the binding affinity of pyoverdines to their cognate or non-cognate Fpv's. The uptake is probably energized by the direct interaction of FpvA with the TonB-ExbBD complex at the ener- gized inner membrane, which transduces sufficient energy to the outer membrane for transport $[95,96]$. P. aeruginosa has two TonB homologs, and albeit TonB1 seems to be more important for iron uptake, TonB2 can partially fulfill the function of TonB1 [97].

FpvA not only binds ferripyoverdine but also to the iron-free apo-pyoverdine, which is not imported but exchanged by ferripyoverdine that is then imported [98-100]. The exchange appears to be accelerated by TonB [99]. However, it has been suggested that the observation regarding binding of apo-pyoverdine by FpvA might be an artifact and that the detected binding could be due to trace-contaminations of aluminum chelates [101, 102]. Indeed, FpvA can bind a wide range of other pyoverdinemetal complexes that in case of $\mathrm{Cu}^{2+}, \mathrm{Ga}^{3+}, \mathrm{Mn}^{2+}$ and $\mathrm{Ni}^{2+}$ may even be imported, albeit with a reduced rate. Furthermore, pyoverdine chelates of $\mathrm{Al}^{3+}, \mathrm{Cu}^{2+}, \mathrm{Ga}^{3+}, \mathrm{Mn}^{2+}, \mathrm{Ni}^{2+}$ and $\mathrm{Zn}^{2+}$ can induce pyoverdine production by binding to FpvA [103]. Some strains possess several FpvA homologs with distinct or overlapping specificities for pyoverdines. A very extensive investigation in this matter was performed by Hartney et al. in 2013, who demonstrated the specificity of a multitude of Fpv homologs and their pyoverdinescavenging potential in $P$. protegens Pf-5 [104].

After import, pyoverdine is not degraded or modified, nor is it imported into the cytoplasm. Instead, $\mathrm{Fe}^{3+}$ is reduced to $\mathrm{Fe}^{2+}$ periplasmically, liberated from pyoverdine, and taken up by the ABC transporter FpvDE [105]. Involved components are encoded in the fpvGHJK and fpvCDEF operons [106]. The inner membrane proteins FpvG and FpvH are essential for iron release, and there is indirect evidence that FpvG catalyzes the reduction step [106]. The other components, such as FpvJ, FpvK, or even the $A B C$ transporter FpvDE and its two soluble periplasmic binding proteins FpvC and FpvF, affect the release partially [106]. As expected for a binding protein of a ferrous iron $A B C$ transporter, there is indirect experimental evidence for chelation of ferrous iron by FpvC [106]. The thus recycled apopyoverdine is reexported as described above into the extracellular compartment by OpmQ-PvdRT $[77,78]$. It has also been reported that pyoverdine can be stored in the periplasmic compartment [42] but this process is not yet understood [107].

\section{Regulation of pyoverdine production - iron limitation and beyond}

As mentioned in the introduction, iron starvation is the key signal for pyoverdine production. The regulator Fur senses ferrous iron ions in the cytoplasm and represses genes involved in iron uptake, including those encoding the regulatory proteins FpvR, Fpvl, and PvdS [11, 72, 108-110]. $\mathrm{PvdS}$ is a sigma factor required for the expression of pyoverdine biosynthesis genes and other, often virulencerelated genes [111-118], Fpvl is a sigma factor required for the genes encoding the outer membrane pyoverdine receptor/importer FpvA [119, 120], and FpvR is an anti-sigma factor that binds to and thereby inactivates PvdS and Fpvl $[119,121]$. FpvR autoproteolytic cleaves itself at a periplasmic domain without any further degradation unless 
it contacts ferripyoverdine-bound FpvA [122, 123]. When this FpvR/FpvA contact occurs, which involves the activity of TonB (the transport-energizing inner membrane protein; see section on import above) [124], further proteolytic events that engage the protease RseP result in liberation of PvdS and Fpvl and activation of their regulated genes [119, $120,122,123,125,126]$. As the cascade begins with the sensing of a receptor-bound ferripyoverdine, it is noteworthy that some ferripyoverdine is required to activate the production of pyoverdine. In the absence of ferripyoverdine, the system therefore adjusts a basal level of PvdS and Fpvl dependent gene expression, caused by a low abundance of FpvR, and this basal expression is required for the above described pyoverdine-dependent sensing pathway [127]. In agreement with this view, mutants defective in pyoverdine production cannot upregulate the PvdS regulon under iron-limiting conditions $[128,129]$. Finally, it is important to emphasize that the regulatory pathways for the production of pyoverdine play important roles beyond pyoverdine production. As mentioned above, the PvdS regulon also includes genes that are not involved in pyoverdine biosynthesis. In $P$. aeruginosa, such genes are clearly contributing to virulence, as the suppressed virulence of a $p v d A$ deletion strain that lacks pyoverdines could be partially restored by deletion of the $f p v R$ gene that encodes the anti-sigma factor FpvR [121]. This $p v d A / f p v R$ double mutant strain constitutively expresses the PvdS- dependent genes without producing pyoverdines. Pyoverdines that are initially sensed by the regulatory cascade thus can serve as signaling molecules in host environments. The above principal signaling pathway is summarized in Figure 4.

Interestingly, the regulation of pyoverdine biosynthesis is even more complex, because signals other than iron starvation have modulating effects. Among these are influences by the regulator CysB [130], which may imply a coordination with sulfur availability or biofilm formation and alginate production [131]. Also phosphate starvation has been reported to trigger pyoverdine production in host environments [132, 133]. Additionally, the LexR type transcriptional regulator $A m p R$, which affects expression of more than 500 genes related to metabolism and virulence in $P$. aeruginosa, has recently been implicated in the regulation of pyoverdine production [134], and also the level of bis- $\left(3^{\prime}-5^{\prime}\right)$-cyclic dimeric guanosine monophosphate (c-diGMP) is reported to modulate pyoverdine production [135].

\section{Concluding remarks}

Pyoverdines play important roles for many pathogenic and non-pathogenic pseudomonads that thrive in host habitats. It is important to understand the biosynthesis of pyoverdines, and this review intends to give a brief survey about our current knowledge and the open questions. There are still some components unknown and some catalytic mech-

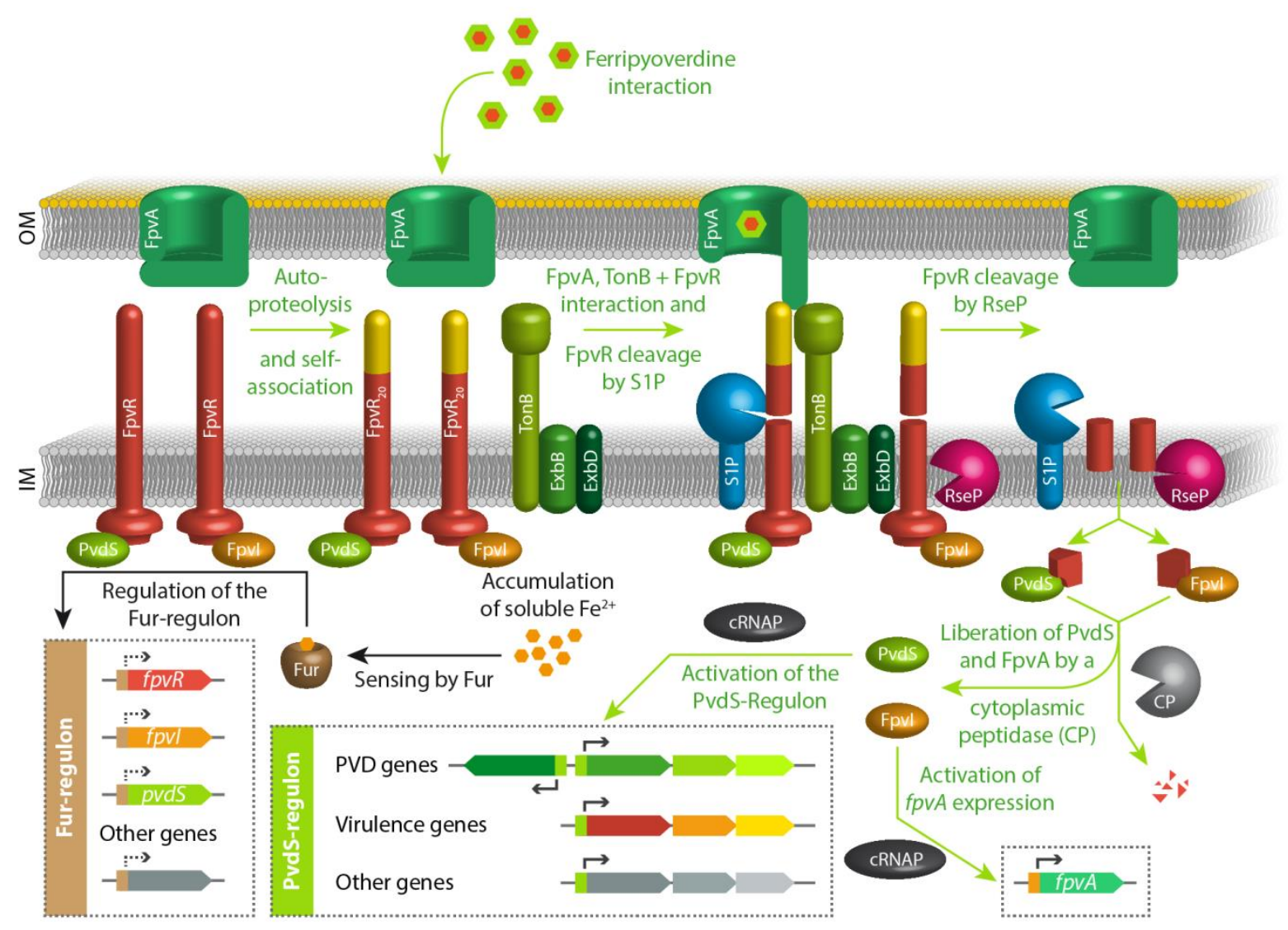

FIGURE 4: The key regulatory pathways for pyoverdine production in response to iron starvation. See text for details. 
anisms not understood. Beside the basics of biosynthesis, the physiological aspects will become more important in future, as the process has to be understood in terms of cell biology, communication, and host interaction. One of these aspects is regulation, which seems to become more complex and interwoven with multiple other regulatory pathways, ranging from biofilm formation to nutrient supply. Future will reveal what else we can learn from pyoverdines.

\section{ACKNOWLEDGMENTS}

The publication of this article was funded by the Open Access fund of Leibniz Universität Hannover. This work was supported by grant BR 2285/7-1 of the German Science Foundation (DFG) to TB.

\section{REFERENCES}

1. Gessard MC (1892). Sur la fonction fluorescigène des microbes. In: Annales de l'Institut Pasteur. (Institut Pasteur, Eds), pp. 801-823. Masson, Paris.

2. Turfreijer A (1941). Pyoverdinen, de groen fluoresceerende kleurstoffen van pseudomonas fluorescens. Proefschrift, Univ. Amsterdam.

3. Turfitt GE (1936). Bacteriological and biochemical relationships in the pyocyaneus-fluorescens group: The chromogenic function in relation to classification. Biochem J 30 (8): 1323-1328. doi: 10.1042/bj0301323

4. Kloepper JW, Leong J, Teintze M and Schroth MN (1980). Enhanced plant growth by siderophores produced by plant growth-promoting rhizobacteria. Nature 286 (5776): 885-886. doi: 10.1038/286885a0

5. Teintze $M$, Hossain $M B$, Barnes $C L$, Leong $J$ and van der Helm $D$ (1981). Structure of ferric pseudobactin. Biochemistry 20 (22): 64466457. doi: 10.1021/bi00525a025

6. King JV, Campbell JJR and Eagles BA (1948). The mineral requirements for fluorescin production. Can J Res 26c (6): 514-519. doi: 10.1139/cjr48c-036

7. Totter JR and Moseley FT (1953). Influence of the concentration of iron on the production of fluorescin by Pseudomonas aeruginosa. J Bacteriol 65 (1): 45-47. PMID: 13022627

8. Meyer JM, and Abdallah MA (1978). The fluorescent pigment of Pseudomonas fluorescens. J Gen Microbiol 107 (2): 319-328. doi: 10.1099/00221287-107-2-319

9. Meyer JM and Hornsperger JM (1978). Role of pyoverdine pf $^{\text {, the }}$ iron-binding fluorescent pigment of Pseudomonas fluorescens, in iron transport. J Gen Microbiol 107 (2): 329-331. doi: 10.1099/00221287107-2-329

10. Lankford CE and Byers BR (1973). Bacterial assimilation of iron. Crit Rev Microbiol 2 (3): 273-331. doi: 10.3109/10408417309108388

11. Pasqua M, Visaggio D, Lo Sciuto A, Genah S, Banin E, Visca P and Imperi $F$ (2017). The ferric uptake regulator Fur is conditionally essential in Pseudomonas aeruginosa. J Bacteriol 199: e00472-17. doi: 10.1128/JB.00472-17

12. Hassett DJ, Sokol PA, Howell ML, Ma JF, Schweizer HT, Ochsner U and Vasil ML (1996). Ferric uptake regulator (Fur) mutants of Pseudomonas aeruginosa demonstrate defective siderophore-mediated iron uptake, altered aerobic growth, and decreased superoxide dismutase and catalase activities. J Bacteriol 178 (14): 3996-4003. doi:

10.1128/jb.178.14.3996-4003.1996

\section{CONFLICT OF INTEREST}

The authors declare no conflict of interest.

\section{COPYRIGHT}

(C) 2018 Ringel and Brüser. This is an open-access article released under the terms of the Creative Commons Attribution (CC BY) license, which allows the unrestricted use, distribution, and reproduction in any medium, provided the original author and source are acknowledged.

Please cite this article as: Michael T. Ringel and Thomas Brüser (2018). The biosynthesis of pyoverdines. Microbial Cell 5(10): 424 437. doi: $10.15698 / \mathrm{mic} 2018.10 .649$

13. Budzikiewicz H (2004). Siderophores of the Pseudomonadaceae sensu stricto (fluorescent and non-fluorescent Pseudomonas spp.). In: Progress in the chemistry of organic natural products. (Falk, H. and Kirby, G.W., Ed), pp. 81-205. Springer, Vienna.

14. Cézard C, Farvacques N and Sonnet P (2015). Chemistry and biology of pyoverdines, Pseudomonas primary siderophores. Curr Med Chem 22 (2): 165-186. doi: 10.2174/0929867321666141011194624

15. Meyer JM (2000). Pyoverdines: pigments, siderophores and potential taxonomic markers of fluorescent Pseudomonas species. Arch Microbiol 174 (3): 135-142. doi: 10.1007/s002030000188

16. Jacques $P$, Ongena $M$, Gwose I, Seinsche $D$, Schröder $H$, Delfosse $P$ Thonart $\mathrm{P}$, Taraz K and Budzikiewicz H (1995). Structure and characterization of isopyoverdin from Pseudomonas putida BTP1 and its relation to the biogenetic pathway leading to pyoverdins. Z Naturforsch $\mathbf{C}$ 50(9-10):622-9. PMID: 8579680

17. Jacques P, Gwose I, Seinsche D, Taraz K, Budzikiewicz H, Schröder $H$, Ongena $M$ and Thonart $P$ (1993). Isopyoverdin Pp BTP 1, a biogenetically interesting novel siderophore from Pseudomonas putida. Nat Prod Lett 3 (3): 213-218. doi: 10.1080/10575639308043866

18. Mossialos D, Ochsner U, Baysse C, Chablain P, Pirnay J-P, Koedam $\mathrm{N}$, Budzikiewicz $\mathrm{H}$, Fernández DU, Schäfer $\mathrm{M}$, Ravel J and Cornelis $\mathrm{P}$ (2002). Identification of new, conserved, non-ribosomal peptide synthetases from fluorescent pseudomonads involved in the biosynthesis of the siderophore pyoverdine. Mol Microbiol 45 (6): 1673-1685. doi: 10.1046/j.1365-2958.2002.03120.x

19. Lehoux DE, Sanschagrin F and Levesque RC (2000). Genomics of the 35-kb pvd locus and analysis of novel pvdIJK genes implicated in pyoverdine biosynthesis in Pseudomonas aeruginosa. FEMS Microbiol Lett 190 (1): 141-146. doi: 10.1111/j.1574-6968.2000.tb09276.x

20. Merriman TR, Merriman ME and Lamont IL (1995). Nucleotide sequence of $p v d D$, a pyoverdine biosynthetic gene from Pseudomonas aeruginosa: PvdD has similarity to peptide synthetases. J Bacteriol 177 (1): 252-258. doi: 10.1128/jb.177.1.252-258.1995

21. Ackerley DF, Caradoc-Davies TT and Lamont IL (2003). Substrate specificity of the nonribosomal peptide synthetase PvdD from Pseudomonas aeruginosa. J Bacteriol 185 (9): 2848-2855. doi: 10.1128/JB.185.9.2848-2855.2003

22. Hohlneicher U, Schäfer M, Fuchs R and Budzikiewicz H (2001). Ferribactins as the biosynthetic precursors of the Pseudomonas siderophores pyoverdins. Z Naturforsch C 56 3-4: 308-310. doi: 10.1515/znc-2001-3-423 
23. Visca P, Imperi F and Lamont IL (2007). Pyoverdine siderophores: from biogenesis to biosignificance. Trends Microbiol 15 (1): 22-30. doi: 10.1016/j.tim.2006.11.004

24. Bloudoff K and Schmeing TM (2017). Structural and functional aspects of the nonribosomal peptide synthetase condensation domain superfamily. Biochim Biophys Acta 1865(11 Pt B):1587-1604. doi: 10.1016/j.bbapap.2017.05.010

25. Drake EJ and Gulick AM (2016). 1.2 Å resolution crystal structure of the periplasmic aminotransferase PvdN from Pseudomonas aeruginosa. Acta Crystallogr F Struct Biol Commun 72(Pt 5):403-8. doi: 10.1107/S2053230X16006257

26. Hannauer $M$, Schäfer $M$, Hoegy F, Gizzi $P$, Wehrung $P$, Mislin GLA, Budzikiewicz $\mathrm{H}$, and Schalk IJ (2012). Biosynthesis of the pyoverdine siderophore of Pseudomonas aeruginosa involves precursors with a myristic or a myristoleic acid chain. FEBS Lett 586 (1): 96-101. doi: 10.1016/j.febslet.2011.12.004

27. Vandenende CS, Vlasschaert M and Seah SYK (2004). Functional characterization of an aminotransferase required for pyoverdine siderophore biosynthesis in Pseudomonas aeruginosa PAO1. J Bacteriol 186 (17): 5596-5602. doi: 10.1128/JB.186.17.5596-5602.2004

28. Visca $P$, Serino $L$ and Orsi $N$ (1992). Isolation and characterization of Pseudomonas aeruginosa mutants blocked in the synthesis of pyoverdin. J Bacteriol 174 (17): 5727-5731. doi: 10.1128/jb.174.17.57275731.1992

29. Visca P, Ciervo A and Orsi N (1994). Cloning and nucleotide sequence of the $p v d A$ gene encoding the pyoverdin biosynthetic enzyme L-ornithine $N^{5}$-oxygenase in Pseudomonas aeruginosa. J Bacteriol 176 (4): 1128-1140. doi: 10.1128/jb.176.4.1128-1140.1994

30. Ge L and Seah SYK (2006). Heterologous expression, purification, and characterization of an L-Ornithine $N^{5}$-hydroxylase involved in pyoverdine siderophore biosynthesis in Pseudomonas aeruginosa. J Bacteriol 188 (20): 7205-7210. doi: 10.1128/JB.00949-06

31. Meneely KM, Barr EW, Bollinger JM and Lamb AL (2009). Kinetic mechanism of ornithine hydroxylase (PvdA) from Pseudomonas aeruginosa: substrate triggering of $\mathrm{O}_{2}$ addition but not flavin reduction. Biochemistry 48 (20): 4371-4376. doi: 10.1021/bi900442z

32. McMorran BJ, Shanta Kumara HM, Sullivan K and Lamont IL (2001). Involvement of a transformylase enzyme in siderophore synthesis in Pseudomonas aeruginosa. Microbiology 147(Pt 6):1517-24. doi: 10.1099/00221287-147-6-1517

33. Imperi F and Visca $P$ (2013). Subcellular localization of the pyoverdine biogenesis machinery of Pseudomonas aeruginosa: a membraneassociated "siderosome". FEBS Lett 587 (21): 3387-3391. doi: 10.1016/j.febslet.2013.08.039

34. Gasser V, Guillon L, Cunrath O and Schalk IJ (2015). Cellular organization of siderophore biosynthesis in Pseudomonas aeruginosa: Evidence for siderosomes. J Inorg Biochem 148: 27-34. doi: 10.1016/j.jinorgbio.2015.01.017

35. Felnagle EA, Barkei JJ, Park H, Podevels AM, McMahon MD, Drott DW and Thomas MG (2010). MbtH-like proteins as integral components of bacterial nonribosomal peptide synthetases. Biochemistry 49 (41): 8815-8817. doi: 10.1021/bi1012854

36. Drake EJ, Cao J, Qu J, Shah MB, Straubinger RM and Gulick AM (2007). The $1.8 \AA$ crystal structure of PA2412, an MbtH-like protein from the pyoverdine cluster of Pseudomonas aeruginosa. J Biol Chem 282 (28): 20425-20434. doi: 10.1074/jbc.M611833200

37. Zhang W, Heemstra JR, Walsh CT and Imker HJ (2010). Activation of the pacidamycin PacL adenylation domain by $\mathrm{MbtH}$-like proteins. Biochemistry 49 (46): 9946-9947. doi: 10.1021/bi101539b
38. Lamont IL and Martin LW (2003). Identification and characterization of novel pyoverdine synthesis genes in Pseudomonas aeruginosa. Microbiology 149 (Pt 4): 833-842. doi: 10.1099/mic.0.26085-0

39. Ravel J and Cornelis P (2003). Genomics of pyoverdine-mediated iron uptake in pseudomonads. Trends Microbiol 11 (5): 195-200. doi: 10.1016/S0966-842X(03)00076-3

40. Lamont IL, Martin LW, Sims T, Scott A and Wallace M (2006). Characterization of a gene encoding an acetylase required for pyoverdine synthesis in Pseudomonas aeruginosa. J Bacteriol 188 (8): 3149-3152. doi: 10.1128/JB.188.8.3149-3152.2006

41. McMorran BJ, Merriman ME, Rombel IT and Lamont IL (1996). Characterisation of the $p v d E$ gene which is required for pyoverdine synthesis in Pseudomonas aeruginosa. Gene 176 (1-2): 55-59. doi: 10.1016/0378-1119(96)00209-0

42. Yeterian E, Martin LW, Guillon L, Journet L, Lamont IL and Schalk IJ (2010). Synthesis of the siderophore pyoverdine in Pseudomonas aeruginosa involves a periplasmic maturation. Amino Acids 38 (5): 1447-1459. doi: 10.1007/s00726-009-0358-0

43. Saurin W, Hofnung M and Dassa E (1999). Getting in or out. J Mol Evol 48 (1): 22-41. doi: 10.1007/pl00006442

44. Tsuda M, Miyazaki H and Nakazawa T (1995). Genetic and physical mapping of genes involved in pyoverdin production in Pseudomonas aeruginosa PAO. J Bacteriol 177 (2): 423-431. doi:

10.1128/jb.177.2.423-431.1995

45. Clevenger KD, Mascarenhas R, Catlin D, Wu R, Kelleher NL, Drake EJ, Gulick AM, Liu D and Fast W (2017). Substrate Trapping in the Siderophore Tailoring Enzyme PvdQ. ACS Chem Biol 12 (3): 643-647. doi: 10.1021/acschembio.7b00031

46. Bokhove M, Nadal Jimenez P, Quax WJ and Dijkstra BW (2010). The quorum-quenching $N$-acyl homoserine lactone acylase $P v d Q$ is an Ntn-hydrolase with an unusual substrate-binding pocket. Proc Natl Acad Sci U S A 107 (2): 686-691. doi: 10.1073/pnas.0911839107

47. Huang JJ, Han J-I, Zhang L-H and Leadbetter JR (2003). Utilization of acyl-homoserine lactone quorum signals for growth by a soil pseudomonad and Pseudomonas aeruginosa PAO1. Appl Environ Microbiol 69 (10): 5941-5949. doi: 10.1128/aem.69.10.5941-5949.2003

48. Sio CF, Otten LG, Cool RH, Diggle SP, Braun PG, Bos R, Daykin M, Cámara M, Williams $P$ and Quax WJ (2006). Quorum quenching by an $\mathrm{N}$-acyl-homoserine lactone acylase from Pseudomonas aeruginosa PAO1. Infect Immun 74 (3): 1673-1682. doi: 10.1128/IAI.74.3.16731682.2006

49. Hall S, McDermott C, Anoopkumar-Dukie S, McFarland AJ, Forbes A, Perkins AV, Davey AK, Chess-Williams R, Kiefel MJ, Arora D and Grant GD (2016). Cellular effects of pyocyanin, a secreted virulence factor of Pseudomonas aeruginosa. Toxins 8 (8). doi: $10.3390 /$ toxins 8080236

50. Nadal Jimenez P, Koch G, Papaioannou E, Wahjudi M, Krzeslak J, Coenye T, Cool RH and Quax WJ (2010). Role of PvdQ in Pseudomonas aeruginosa virulence under iron-limiting conditions. Microbiology 156 (Pt 1): 49-59. doi: 10.1099/mic.0.030973-0

51. Drake EJ and Gulick AM (2011). Structural characterization and high-throughput screening of inhibitors of PvdQ, an NTN hydrolase involved in pyoverdine synthesis. ACS Chem Biol 6 (11): 1277-1286. doi: 10.1021/cb2002973

52. Wurst JM, Drake EJ, Theriault JR, Jewett IT, VerPlank L, Perez JR, Dandapani S, Palmer M, Moskowitz SM, Schreiber SL, Munoz B and Gulick AM (2014). Identification of inhibitors of PvdQ, an enzyme involved in the synthesis of the siderophore pyoverdine. ACS Chem Biol 9 (7): 1536-1544. doi: 10.1021/cb5001586 
53. Clevenger KD, Wu R, Er JAV, Liu D and Fast W (2013). Rational design of a transition state analogue with picomolar affinity for Pseudomonas aeruginosa $\mathrm{PvdQ}$, a siderophore biosynthetic enzyme. ACS Chem Biol 8 (10): 2192-2200. doi: 10.1021/cb400345h

54. Hohlneicher U, Hartmann R, Taraz K and Budzikiewicz H (1992). The Structure of Ferribactin from Pseudomonas fluorescens ATCC 13525. Z Naturforsch B 47 (11). doi: 10.1515/znb-1992-1119

55. Dorrestein PC, Poole K and Begley TP (2003). Formation of the chromophore of the pyoverdine siderophores by an oxidative cascade. Org Lett 5 (13): 2215-2217. doi: 10.1021/ol034531e

56. Nadal-Jimenez P, Koch G, Reis CR, Muntendam R, Raj H, Jeronimus-Stratingh CM, Cool RH and Quax WJ (2014). PvdP is a tyrosinase that drives maturation of the pyoverdine chromophore in Pseudomonas aeruginosa. J Bacteriol 196 (14): 2681-2690. doi:

10.1128/JB.01376-13

57. Jacques $P$, Ongena $M$, Bernard $F$, Fuchs $R$, Budzikiewicz $H$ and Thonart $P$ (2003). Fluorescent Pseudomonas mainly produce the dihydroform of pyoverdine at low specific growth rate. Lett Appl Microbiol 36 (5): 259-262. doi: 10.1046/j.1472-765X.2003.01304.x

58. Bultreys A, Gheysen I, Maraite H and de Hoffmann E (2001). Characterization of fluorescent and nonfluorescent peptide siderophores produced by Pseudomonas syringae strains and their potential use in strain identification. Appl Environ Microbiol 67 (4): 1718-1727. doi: 10.1128/AEM.67.4.1718-1727.2001

59. Teintze $M$ and Leong J (1981). Structure of pseudobactin A, a second siderophore from plant growth promoting Pseudomonas B10. Biochemistry 20 (22): 6457-6462. doi. 10.1021/bi00525a026

60. Ringel MT, Dräger $G$ and Brüser T (2017). PvdO is required for the oxidation of dihydropyoverdine as last step of fluorophore formation in Pseudomonas fluorescens. J Biol Chem 293 (7): 2330-2341. doi: 10.1074/jbc.RA117.000121

61. Longerich I, Taraz K, Budzikiewicz H, Tsai L and Meyer JM (1993). Pseudoverdin, a compound related to the pyoverdin chromophore from a Pseudomonas aeruginosa strain incapable to produce pyoverdins. Z Naturforsch C 48 5-6: 425-429. PMID: 8363709

62. Schröder H, Taraz JAK and Budzikiewicz H (1995). Dihydropyoverdinsulfonsäuren - Zwischenstufen bei der Biogenese? Z Naturforsch C 50 9-10: 616-621. doi: 10.1515/znc-1995-9-1004

63. Budzikiewicz H (2006). Bacterial aromatic sulfonates - A bucherer reaction in nature? Mini-Reviews in Organic Chemistry 3 (2): 93-97. doi: 10.2174/157019306776819262

64. Baysse C, Budzikiewicz H, Uría Fernández D and Cornelis P (2002). Impaired maturation of the siderophore pyoverdine chromophore in Pseudomonas fluorescens ATCC 17400 deficient for the cytochrome $c$ biogenesis protein CcmC. FEBS Lett 523 (1-3): 23-28. doi: 10.1016/S0014-5793(02)02915-0

65. Gaballa A, Koedam N and Cornelis P (1996). A cytochrome $c$ biogenesis gene involved in pyoverdine production in Pseudomonas fluorescens ATCC 17400. Mol Microbiol 21 (4): 777-785. doi: 10.1046/j.1365-2958.1996.391399.x

66. Gaballa A, Baysse C, Koedam N, Muyldermans S and Cornelis P (1998). Different residues in periplasmic domains of the CcmC inner membrane protein of Pseudomonas fluorescens ATCC 17400 are critical for cytochrome $c$ biogenesis and pyoverdine-mediated iron uptake. Mol Microbiol 30 (3): 547-555. doi: 10.1046/j.13652958.1998.01085.x

67. Ahuja $U$ and Thöny-Meyer $L$ (2005). CcmD is involved in complex formation between $\mathrm{CcmC}$ and the heme chaperone CcmE during cytochrome c maturation. J Biol Chem 280 (1): 236-243. doi:

10.1074/jbc.M410912200
68. Ahuja $U$ and Thöny-Meyer $L$ (2003). Dynamic features of a heme delivery system for cytochrome $C$ maturation. J Biol Chem 278 (52): 52061-52070. doi: 10.1074/jbc.M310077200

69. Feissner RE, Richard-Fogal CL, Frawley ER and Kranz RG (2006). $A B C$ transporter-mediated release of a haem chaperone allows cytochrome c biogenesis. Mol Microbiol 61 (1): 219-231. doi: 10.1111/j.1365-2958.2006.05221.x

70. Richard-Fogal C and Kranz RG (2010). The CcmC:heme:CcmE complex in heme trafficking and cytochrome c biosynthesis. J Mol Biol 401 (3): 350-362. doi: 10.1016/j.jmb.2010.06.041

71. Ringel MT, Dräger G and Brüser T (2016). PvdN enzyme catalyzes a periplasmic pyoverdine modification. J Biol Chem 291 (46): 2392923938. doi: 10.1074/jbc.M116.755611

72. Ochsner UA, Wilderman PJ, Vasil AI and Vasil ML (2002).

GeneChip ${ }^{\circledR}$ expression analysis of the iron starvation response in Pseudomonas aeruginosa. Mol Microbiol 45 (5): 1277-1287. doi: 10.1046/j.1365-2958.2002.03084.x

73. Voulhoux R, Filloux A and Schalk IJ (2006). Pyoverdine-mediated iron uptake in Pseudomonas aeruginosa: the Tat system is required for PvdN but not for FpvA transport. J Bacteriol 188 (9): 3317-3323. doi: 10.1128/JB.188.9.3317-3323.2006

74. Ringel $M T$, Dräger $G$ and Brüser $T$ (2017). The periplasmic transaminase PtaA of Pseudomonas fluorescens converts the glutamic acid residue at the pyoverdine fluorophore to $\alpha$-ketoglutaric acid. J Biol Chem 292 (45): 18660-18671. doi: 10.1074/jbc.M117.812545

75. Budzikiewicz H, Schäfer M, Fernández DU, Matthijs S and Cornelis $P$ (2007). Characterization of the chromophores of pyoverdins and related siderophores by electrospray tandem mass spectrometry. Biometals 20 (2): 135-144. doi: 10.1007/s10534-006-9021-3

76. Hannauer M, Yeterian E, Martin LW, Lamont IL and Schalk IJ (2010). An efflux pump is involved in secretion of newly synthesized siderophore by Pseudomonas aeruginosa. FEBS Lett 584 (23): 47514755. doi: 10.1016/j.febslet.2010.10.051

77. Yeterian E, Martin LW, Lamont IL and Schalk IJ (2010). An efflux pump is required for siderophore recycling by Pseudomonas aeruginosa. Environ Microbiol Rep 2 (3): 412-418. doi: 10.1111/j.17582229.2009.00115.x

78. Imperi F, Tiburzi F and Visca P (2009). Molecular basis of pyoverdine siderophore recycling in Pseudomonas aeruginosa. Proc Natl Acad Sci U S A 106 (48): 20440-20445. doi: 10.1073/pnas.0908760106

79. Poole K, Krebes K, McNally C and Neshat S (1993). Multiple antibiotic resistance in Pseudomonas aeruginosa: evidence for involvement of an efflux operon. J Bacteriol 175 (22): 7363-7372. doi: 10.1128/jb.175.22.7363-7372.1993

80. Poole K, Heinrichs DE and Neshat S (1993). Cloning and sequence analysis of an EnvCD homologue in Pseudomonas aeruginosa. Mol Microbiol 10 (3): 529-544. doi: 10.1111/j.1365-2958.1993.tb00925.x

81. Li XZ, Nikaido $\mathrm{H}$ and Poole K (1995). Role of mexA-mexB-oprM in antibiotic efflux in Pseudomonas aeruginosa. Antimicrob Agents Chemother 39 (9): 1948-1953. doi: 10.1128/aac.39.9.1948

82. Chen W-J, Kuo T-Y, Hsieh F-C, Chen P-Y, Wang C-S, Shih Y-L, Lai YM, Liu J-R, Yang Y-L and Shih M-C (2016). Involvement of type VI secretion system in secretion of iron chelator pyoverdine in Pseudomonas taiwanensis. Sci Rep 6: 32950. doi: 10.1038/srep32950

83. Hohnadel D and Meyer JM (1988). Specificity of pyoverdinemediated iron uptake among fluorescent Pseudomonas strains. J Bacteriol 170 (10): 4865-4873. doi: 10.1128/jb.170.10.48654873.1988 
84. Cornelis P, Hohnadel D and Meyer JM (1989). Evidence for different pyoverdine-mediated iron uptake systems among Pseudomonas aeruginosa strains. Infect Immun 57 (11): 3491-3497. PMID: 2509364

85. Meyer JM, Hohnadel D, Khan A and Cornelis P (1990). Pyoverdinfacilitated iron uptake in Pseudomonas aeruginosa: immunological characterization of the ferripyoverdin receptor. Mol Microbiol 4 (8): 1401-1405. doi: 10.1111/j.1365-2958.1990.tb00719.x

86. Poole K, Neshat S and Heinrichs D (1991). Pyoverdine-mediated iron transport in Pseudomonas aeruginosa. FEMS Microbiol Lett 78 (1): 1-6. doi: 10.1111/j.1574-6968.1991.tb04406.x

87. Poole K, Neshat S, Krebes K and Heinrichs DE (1993). Cloning and nucleotide sequence analysis of the ferripyoverdine receptor gene fpvA of Pseudomonas aeruginosa. J Bacteriol 175 (15): 4597-4604. doi: 10.1128/jb.175.15.4597-4604.1993

88. Cobessi D, Celia H, Folschweiller N, Schalk IJ, Abdallah MA and Pattus $F$ (2005). The crystal structure of the pyoverdine outer membrane receptor FpvA from Pseudomonas aeruginosa at 3.6 angstroms resolution. J Mol Biol 347 (1): 121-134. doi:

10.1016/j.jmb.2005.01.021

89. Wirth C, Meyer-Klaucke W, Pattus F and Cobessi D (2007). From the periplasmic signaling domain to the extracellular face of an outer membrane signal transducer of Pseudomonas aeruginosa: crystal structure of the ferric pyoverdine outer membrane receptor. J Mol Biol 368 (2): 398-406. doi: 10.1016/j.jmb.2007.02.023

90. Brillet $K$, Journet L, Célia H, Paulus L, Stahl A, Pattus F and Cobessi $D$ (2007). A $\beta$ strand lock exchange for signal transduction in TonBdependent transducers on the basis of a common structural motif. Structure 15 (11): 1383-1391. doi: 10.1016/j.str.2007.08.013

91. James HE, Beare PA, Martin LW and Lamont IL (2005). Mutational analysis of a bifunctional ferrisiderophore receptor and signaltransducing protein from Pseudomonas aeruginosa. J Bacteriol 187 (13): 4514-4520. doi: 10.1128/JB.187.13.4514-4520.2005

92. Shen J-S, Geoffroy V, Neshat S, Jia Z, Meldrum A, Meyer J-M and Poole K (2005). FpvA-mediated ferric pyoverdine uptake in Pseudomonas aeruginosa. J Bacteriol 187 (24): 8511-8515. doi: 10.1128/JB.187.24.8511-8515.2005

93. Nader M, Dobbelaere W, Vincent M, Journet L, Adams H, Cobessi D, Gallay J and Schalk IJ (2007). Identification of residues of FpvA involved in the different steps of Pvd-Fe uptake in Pseudomonas aeruginosa. Biochemistry 46 (42): 11707-11717. doi: 10.1021/bi700997w

94. Greenwald J, Nader M, Celia H, Gruffaz C, Geoffroy V, Meyer J $M$, Schalk IJ, Pattus F (2009). FpvA bound to non-cognate pyoverdines: molecular basis of siderophore recognition by an iron transporter. Mol Microbiol 72 (5): 1246-1259. doi 10.1111/j.13652958.2009.06721.x

95. Adams H, Zeder-Lutz G, Schalk I, Pattus F and Celia H (2006). Interaction of TonB with the outer membrane receptor FpvA of Pseudomonas aeruginosa. J Bacteriol 188 (16): 5752-5761. doi: 10.1128/JB.00435-06

96. Nader M, Journet L, Meksem A, Guillon L and Schalk IJ (2011). Mechanism of ferripyoverdine uptake by Pseudomonas aeruginosa outer membrane transporter FpvA. Biochemistry 50 (13): 2530-2540. doi: 10.1021/bi101821n

97. Zhao Q and Poole K (2000). A second tonB gene in Pseudomonas aeruginos $a$ is linked to the exbB and exbD genes. FEMS Microbiol Lett 184 (1): 127-132. doi: 10.1111/j.1574-6968.2000.tb09002.x

98. Schalk IJ, Abdallah MA and Pattus F (2002). A new mechanism for membrane iron transport in Pseudomonas aeruginosa. Biochem Soc Trans 30 (4): 702-705. doi: 10.1042/bst0300702
99. Schalk IJ, Hennard C, Dugave C, Poole K, Abdallah MA and Pattus F (2001). Iron-free pyoverdin binds to its outer membrane receptor FpvA in Pseudomonas aeruginosa. Mol Microbiol 39 (2): 351-361. doi 10.1046/j.1365-2958.2001.02207.x

100. Clément E, Mesini PJ, Pattus F and Schalk IJ (2004). The binding mechanism of pyoverdin with the outer membrane receptor FpvA in Pseudomonas aeruginosa is dependent on its iron-loaded status. Biochemistry 43 (24): 7954-7965. doi: 10.1021/bi049768c

101. Greenwald J, Zeder-Lutz G, Hagege A, Celia H and Pattus F (2008). The metal dependence of pyoverdine interactions with its outer membrane receptor FpvA. J Bacteriol 190 (20): 6548-6558. doi: 10.1128/JB.00784-08

102. Cornelis $P$ (2008). Unexpected interaction of a siderophore with aluminum and its receptor. J Bacteriol 190 (20): 6541-6543. doi: 10.1128/JB.00954-08

103. Braud A, Hoegy F, Jezequel K, Lebeau T and Schalk IJ (2009). New insights into the metal specificity of the Pseudomonas aeruginosa pyoverdine-iron uptake pathway. Environ Microbiol 11 (5): 10791091. doi: 10.1111/j.1462-2920.2008.01838.x

104. Hartney SL, Mazurier S, Girard MK, Mehnaz S, Davis EW, Gross H, Lemanceau $P$ and Loper JE (2013). Ferric-pyoverdine recognition by Fpv outer membrane proteins of Pseudomonas protegens Pf-5. J Bacteriol 195 (4): 765-776. doi: 10.1128/JB.01639-12

105. Brillet K, Ruffenach F, Adams H, Journet L, Gasser V, Hoegy F, Guillon L, Hannauer M, Page A and Schalk IJ (2012). An ABC transporter with two periplasmic binding proteins involved in iron acquisition in Pseudomonas aeruginosa. ACS Chem Biol 7 (12): 2036-2045. doi: 10.1021/cb300330v

106. Ganne G, Brillet K, Basta B, Roche B, Hoegy F, Gasser V and Schalk IJ (2017). Iron release from the siderophore pyoverdine in Pseudomonas aeruginosa involves three new actors: FpvC, FpvG, and FpvH. ACS Chem Biol 12 (4): 1056-1065. doi: 10.1021/acschembio.6b01077

107. Schalk IJ and Guillon L (2013). Pyoverdine biosynthesis and secretion in Pseudomonas aeruginosa: implications for metal homeostasis. Environ Microbiol 15 (6): 1661-1673. doi: 10.1111/1462-2920.12013

108. Ochsner UA and Vasil ML (1996). Gene repression by the ferric uptake regulator in Pseudomonas aeruginosa. Proc Natl Acad Sci U S A 93 (9): 4409-4414. doi: 10.1073/pnas.93.9.4409

109. Palma M, Worgall S and Quadri LEN (2003). Transcriptome analysis of the Pseudomonas aeruginosa response to iron. Arch Microbiol 180 (5): 374-379. doi: 10.1007/s00203-003-0602-z

110. Cornelis P, Matthijs $S$ and van Oeffelen L (2009). Iron uptake regulation in Pseudomonas aeruginosa. Biometals 22 (1): 15-22. doi: 10.1007/s10534-008-9193-0

111. Vasil ML, Ochsner UA, Johnson Z, Colmer JA and Hamood AN (1998). The Fur-regulated gene encoding the alternative sigma factor PvdS is required for iron-dependent expression of the LysR-type regulator PtxR in Pseudomonas aeruginosa. J Bacteriol 180 (24): 67846788. PMID: 9852033

112. Gaines JM, Carty NL, Tiburzi F, Davinic M, Visca P, ColmerHamood JA and Hamood AN (2007). Regulation of the Pseudomonas aeruginosa toxA, regA and ptxR genes by the iron-starvation sigma factor PvdS under reduced levels of oxygen. Microbiology 153 (Pt 12): 4219-4233. doi: 10.1099/mic.0.2007/011338-0

113. Ochsner UA, Johnson Z, Lamont IL, Cunliffe HE and Vasil ML (1996). Exotoxin A production in Pseudomonas aeruginosa requires the iron-regulated $p v d S$ gene encoding an alternative sigma factor. Mol Microbiol 21 (5): 1019-1028. doi: 10.1046/j.13652958.1996.481425.x 
114. Visca $P$ (2004). Iron regulation and siderophore signalling in virulence by Pseudomonas aeruginosa. In: Pseudomonas. (Ramos, J.-L., Eds), pp. 69-123. Springer US, Boston, MA.

115. Wilderman PJ, Vasil AI, Johnson Z, Wilson MJ, Cunliffe HE, Lamont IL and Vasil ML (2001). Characterization of an endoprotease (PrpL) encoded by a PvdS-regulated gene in Pseudomonas aeruginosa. Infect Immun 69 (9): 5385-5394. doi: 10.1128/IAI.69.9.53855394.2001

116. Prince RW, Cox CD and Vasil ML (1993). Coordinate regulation of siderophore and exotoxin A production. J Bacteriol 175 (9): 25892598. doi: 10.1128/jb.175.9.2589-2598.1993

117. Wilson MJ and Lamont IL (2000). Characterization of an ECF sigma factor protein from Pseudomonas aeruginosa. Biochem Biophys Res Commun 273 (2): 578-583. doi: 10.1006/bbrc. 2000.2996

118. Cunliffe HE, Merriman TR and Lamont IL (1995). Cloning and characterization of $p v d S$, a gene required for pyoverdine synthesis in Pseudomonas aeruginosa. J Bacteriol 177 (10): 2744-2750. doi: 10.1128/jb.177.10.2744-2750.1995

119. Rédly GA and Poole K (2005). FpvIR control of fpvA ferric pyoverdine receptor gene expression in Pseudomonas aeruginosa: demonstration of an interaction between Fpvl and FpvR and identification of mutations in each compromising this interaction. J Bacteriol 187 (16): 5648-5657. doi: 10.1128/JB.187.16.5648-5657.2005

120. Rédly GA and Poole K (2003). Pyoverdine-mediated regulation of FpvA synthesis in Pseudomonas aeruginosa. J Bacteriol 185 (4): 12611265. doi: 10.1128/JB.185.4.1261-1265.2003

121. Minandri F, Imperi F, Frangipani E, Bonchi C, Visaggio D, Facchini M, Pasquali P, Bragonzi A and Visca P (2016). Role of iron uptake systems in Pseudomonas aeruginosa virulence and airway infection. Infect Immun 84 (8): 2324-2335. doi: 10.1128/IAI.00098-16

122. Draper RC, Martin LW, Beare PA and Lamont IL (2011). Differential proteolysis of sigma regulators controls cell-surface signalling in Pseudomonas aeruginosa. Mol Microbiol 82 (6): 1444-1453. doi: 10.1111/j.1365-2958.2011.07901.x

123. Bastiaansen KC, Otero-Asman JR, Luirink J, Bitter W and Llamas MA (2015). Processing of cell-surface signalling anti-sigma factors prior to signal recognition is a conserved autoproteolytic mechanism that produces two functional domains. Environ Microbiol 17 (9): 3263-3277. doi: 10.1111/1462-2920.12776

124. Llamas MA, Imperi F, Visca P and Lamont IL (2014). Cell-surface signaling in Pseudomonas: stress responses, iron transport, and pathogenicity. FEMS Microbiol Rev 38 (4): 569-597. doi: 10.1111/15746976.12078

125. Spencer MR, Beare PA and Lamont IL (2008). Role of cell surface signaling in proteolysis of an alternative sigma factor in Pseudomonas aeruginosa. J Bacteriol 190 (14): 4865-4869. doi: 10.1128/JB.0199807

126. Wilson MJ, McMorran BJ and Lamont IL (2001). Analysis of promoters recognized by PvdS, an extracytoplasmic-function sigma factor protein from Pseudomonas aeruginosa. J Bacteriol 183 (6): 21512155. doi: 10.1128/JB.183.6.2151-2155.2001

127. Edgar RJ, Hampton GE, Garcia GPC, Maher MJ, Perugini MA, Ackerley DF and Lamont IL (2017). Integrated activities of two alternative sigma factors coordinate iron acquisition and uptake by Pseudomonas aeruginosa. Mol Microbiol 106 (6): 891-904. doi: 10.1111/mmi.13855

128. Lamont IL, Beare PA, Ochsner U, Vasil AI and Vasil ML (2002). Siderophore-mediated signaling regulates virulence factor production in Pseudomonas aeruginosa. Proc Natl Acad Sci U S A 99 (10): 70727077. doi: 10.1073/pnas.092016999

129. Beare PA, For RJ, Martin LW and Lamont IL (2003). Siderophoremediated cell signalling in Pseudomonas aeruginosa: divergent pathways regulate virulence factor production and siderophore receptor synthesis. Mol Microbiol 47 (1): 195-207. doi: 10.1046/j.13652958.2003.03288.x

130. Imperi F, Tiburzi F, Fimia GM and Visca P (2010). Transcriptional control of the pvdS iron starvation sigma factor gene by the master regulator of sulfur metabolism CysB in Pseudomonas aeruginosa. Environ Microbiol 12 (6): 1630-1642. doi: 10.1111/j.14622920.2010.02210.x

131. Delic-Attree I, Toussaint B, Garin J and Vignais PM (1997). Cloning, sequence and mutagenesis of the structural gene of Pseudomonas aeruginosa $\mathrm{CysB}$, which can activate algD transcription. Mol Microbiol 24 (6): 1275-1284. doi: 10.1046/j.1365-2958.1997.4121799.x

132. Zaborin A, Romanowski K, Gerdes S, Holbrook C, Lepine F, Long J, Poroyko V, Diggle SP, Wilke A, Righetti K, Morozova I, Babrowski T, Liu DC, Zaborina O and Alverdy JC (2009). Red death in Caenorhabditis elegans caused by Pseudomonas aeruginosa PAO1. Proc Natl Acad Sci U S A 106 (15): 6327-6332. doi: 10.1073/pnas.0813199106

133. Zaborin A, Gerdes S, Holbrook C, Liu DC, Zaborina OY and Alverdy JC (2012). Pseudomonas aeruginosa overrides the virulence inducing effect of opioids when it senses an abundance of phosphate. PLoS One 7 (4): e34883. doi: 10.1371/journal.pone.0034883

134. Balasubramanian D, Kumari $H$, Jaric $M$, Fernandez $M$, Turner $\mathrm{KH}$, Dove SL, Narasimhan G, Lory S and Mathee K (2014). Deep sequencing analyses expands the Pseudomonas aeruginosa AmpR regulon to include small RNA-mediated regulation of iron acquisition, heat shock and oxidative stress response. Nucleic Acids Res 42 (2): 979-998. doi: 10.1093/nar/gkt942

135. Chen Y, Yuan M, Mohanty A, Yam JKH, Liu Y, Chua SL, Nielsen TE, Tolker-Nielsen T, Givskov M, Cao B and Yang L (2015). Multiple diguanylate cyclase-coordinated regulation of pyoverdine synthesis in Pseudomonas aeruginosa. Environ Microbiol Rep 7 (3): 498-507. doi: $10.1111 / 1758-2229.12278$ 